\title{
A Linear Laminated Cylindrical Transverse Flux Machine for use with a Free Piston Engine
}

\author{
Junnan Wang, Nick J. Baker
}

\begin{abstract}
This paper discusses the development of a new topology of cylindrical transverse flux linear machine for use with a free piston engine. Despite its three dimensional flux path, the stator of this topology can be made from regular laminated components and only the translator includes soft magnetic composites.

The design development is discussed, including alternative winding and fabrication techniques. Finite element analysis, results of a laboratory prototype and numerical-reluctance analysis are all used to give insight into the machine characteristics. By using flux and flux linkage factors the trade-off between force requirement and power factor is explored. It is shown that the power factor of this topology will generally vary from 0.89-0.6, which compares well with other transverse flux machines.
\end{abstract}

Index Terms--Linear machine, transverse flux, free piston engine

\section{INTRODUCTION}

$\mathrm{T}$ HE heart of most small to medium sized combustion engines is a piston which expands due to the injection of heat energy to a working fluid. Conventionally, the reciprocating linear motion of the piston is converted to a continuous rotating motion via a crankshaft and the heat energy is derived from combustion within the cylinder. In a Free Piston Engine (FPE), there is no conversion to rotary motion and the mechanical load is linear and reciprocating. Potential advantages of this include increased thermal efficiency, reduced frictional loss, a physically compact design and the potential for a flexible compression ratio leading to improved performance at the part load.

In a direct drive free piston engine the reciprocating pistons are used to drive an electrical generator. For example in 2014 Toyota proposed an engine consisting of a two-stroke combustion chamber, a linear generator and a gas spring chamber [1, 2]. The piston is moved by the combustion chamber, thereby converting the kinetic energy to the electrical energy.

\section{The Transverse FluX LineAr Machine}

The Transverse Flux Machine (TFM) is a promising topology that can be attractive to designers who are working on

J. Wang is working towards the $\mathrm{PhD}$ degree in Newcastle University, designing the generator for a free piston engine. high torque or high thrust applications [3]. The force density is a result of being able to decouple the electric and magnetic loading - allowing an increase in pole number without reducing the MMF per pole [4]. Higher pole number machines thus give a higher overall force. The independence between phases also gives good fault tolerance in phase-deficient operation which can increase the system reliability. However, the required 3D flux path prevents the use of simple stacked laminations and often requires the use of Soft Magnetic Composite (SMC) materials or bent laminations to guide the flux around the stator winding [5].

In previous studies $[6,7,8]$ linear versions of TFMs and conventional longitudinal topologies have been discussed when working with a Free-Piston Engine. Simulation results showed that a Modulated Pole Machine TFM topology (MPM) can achieve low copper loss with about $97 \%$ efficiency at low speed, high thrust force density with about $300 \mathrm{~N} / \mathrm{kg}$ or $10.5 \mathrm{kN} / \mathrm{m}^{2}$ and 0.62 power factor for the worst case scenario.
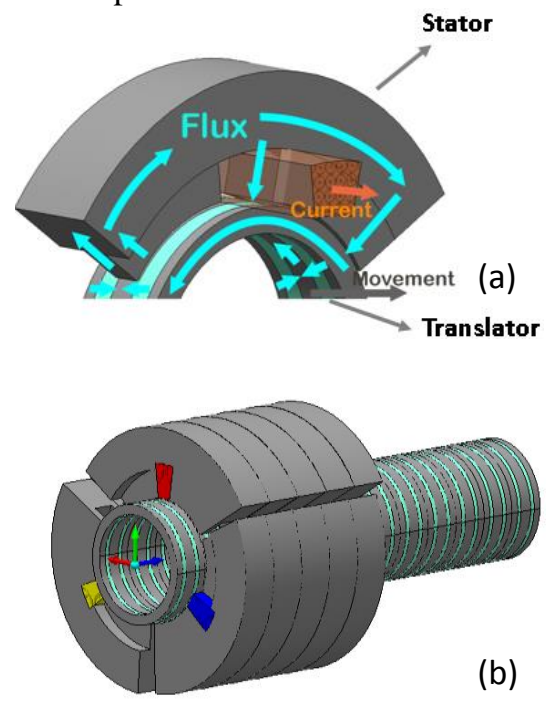

Fig. 1. Base topology (a) flux path of a single phase (b) 3 phase machine

The transverse flux machine topology is normally used for high torque density applications such as electric vehicles [9, 10]. The linear topology has been studied for wave energy [11] and the free piston engine [8]. The flux path of this topology is three dimensioned, precluding the use of a simple laminated structure. Rotary versions of the TFM have been presented

N. J. Baker, is a Senior Lecturer within Newcastle University's Electrical Power Group. He is a machine designer with research projects across the automotive, aerospace and renewable energy sector. 
using SMC [12], laminations [13], or a combination [14]. The advantage of having no competition between space requirements of flux carrying teeth and space occupied by windings is well documented in [15].

The basic topology studied in this paper is given in Fig. 1. In this paper a detailed design study will be presented, followed by a discussion of the manufacturing options and a description of a laboratory prototype. Numerical analysis based on the final design will be used to discuss the machine performance in terms of two flux ratios in the machine.

\section{TOPOLOGY DEVELOPMENT}

Fig. 2 shows three configurations of this topology, starting with the three separate phases shown in Fig. 2 (a). A baseline design of this machine, described in [8], is modelled in commercially available 3D electromagnetic finite element analysis (Infolytica's MagNet) and used to investigate topology developments.

By fully pitching the original separated stator, the mean force is found from finite element analysis models to drop by $6 \%$, Fig. 2 (b). Adjacent phase teeth can subsequently be combined, forming a "combined phase machine" similar to its rotary counterpart [16], Fig. 2(c). This combination can not only recover the force capability but also increase it by $6 \%$. Such a change in the stator tooth can effectively reduce the number of building components without changing the phase EMF harmonics.

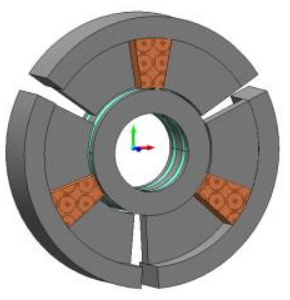

(a)

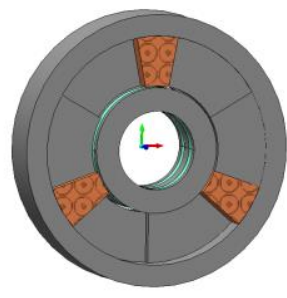

(b)

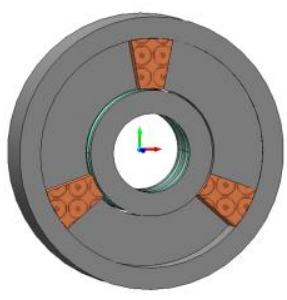

(c)
Fig. 2. Topology development (a) separated stator, (b) full pitch stator (c) combined tooth stator.

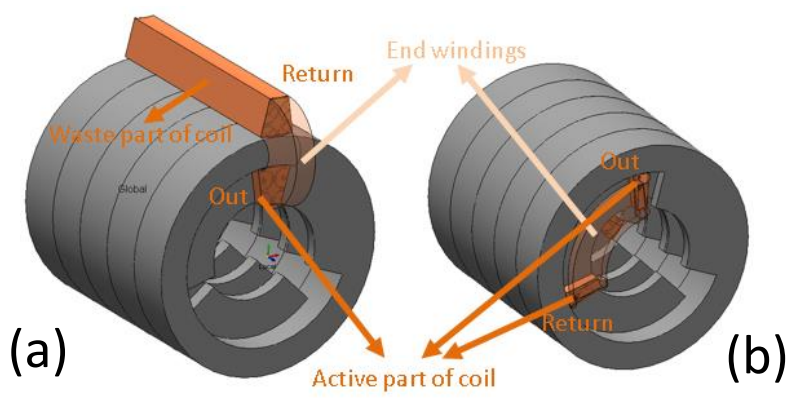

Fig. 3. Winding options (a) return path outside of the machine (b) returned end winding single tooth type winding

In all these three topologies, the return path of the coil is on the outer surface of the stator as presented in Fig. 3(a). By switching to a single toothed type winding as shown in Fig. 3(b), the copper usage can be improved and winding can be simplified. In theory, applying such a winding topology can effectively reduce the copper usage to $50 \%$ (ignoring end windings). However, a drawback of this is the force reduction due to the low winding factor. If the machine dimensions and current density are all maintained then the phase MMF of the single tooth winding will reduce to half of that in (a), meanwhile both out and return coils are contributing to the machine force output. However such winding topology was found to give a $23 \%$ force reduction in simulations. The two sides of the coil are effectively short pitched by $60^{\circ}$, giving a pitch factor of 0.866 , which matches well with the $23 \%$ reduction in force observed.

Such force reduction can simply be redeemed by increasing the phase MMF in the single tooth winding. The final topology shows that it is possible to recuperate the force by increasing the coil area and electric loading whilst still achieving 37\% less copper loss compared to the combined tooth topology with the original windings. What is more, by using the single tooth winding topology the total harmonic distortion of EMF harmonics can be improved by $50 \%$.

\section{MANUfACTURING OPTIONS}

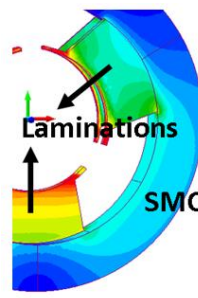

(a)

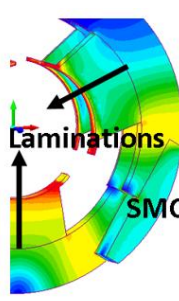

(b)

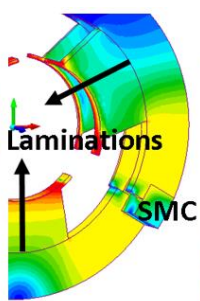

(c)

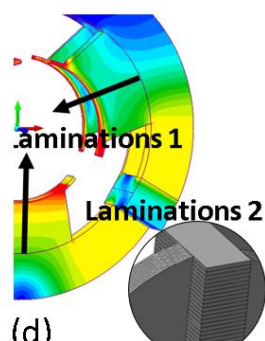

(d)
Fig. 4. Lamination strategies: (a) laminated teeth in an SMC core-back (b) laminated teeth and partially laminated core-back with SMC segment for axial flux flow and radial flux gathering (c) laminated teeth and core-back with SMC segment for axial flux flow (d) laminated teeth and core-back with radially laminated insert

Four alternative construction options are shown in Fig. 4, aiming to reduce reliance on SMC material in the stator. In Fig 4(a), stator teeth are composed of steel laminations where the flux is radially conducted and an SMC core back ring is used to allow flux flow in the circumferential and axial directions. Fig. 4(b) extends the tooth lamination area and replaces the SMC ring with smaller SMC blocks. In Fig. 4(c), a further minimization of the SMC block to a small square cross section is shown. In this case, flux flow in the SMC is primarily in the axial and circumferential direction. In Fig. 4(d) the SMC is replaced by a radially laminated block. In this case, the stator teeth provide a 2D flux path in the $(\mathrm{x}, \mathrm{y})$ plane whereas the radially laminated block provides a 2D flux path in the $(\mathrm{x}, \mathrm{z})$ plane. Thus a 3D flux path can be formed without the use of SMC.

The simulated performance of the four machines are shown in Fig. 5, assuming laminated components are made from M270-35A and the SMC is of a prototyping grade. Compared to commercial grades suitable only for use with pressed components, prototyping SMC has a greater suitability for machining but sacrifices performance: with a lower mass density leading to poorer permeability and lower saturation flux density. However, it can be machined in the same way as solid steel. Simulation results show that the SMC free option (d) has 
$96 \%$ of the magnet driven flux and develops $92 \%$ of the force of the SMC version. Performance of all variants drops compared to the pure SMC core back, as the material available to carry axial flux flow is reduced and there is saturation at the interface. The reduction in force is greater than the reduction of magnet driven flux flow, as the reluctance in the magnetic circuit of the coil driven flux is also affected.

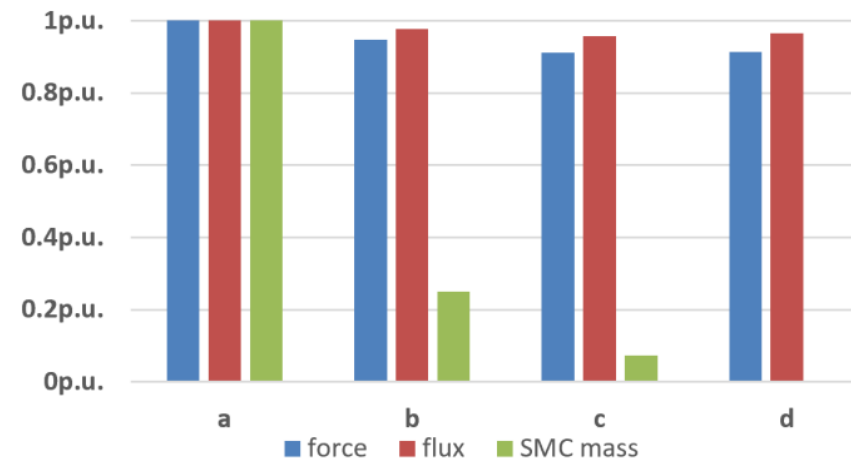

Fig. 5. Performance comparison (where force $=$ force at rated current, flux $=$ open circuit flux, SMC mass = mass of SMC in the stator)

\section{VALIDATION}

\section{A. Fabrication}

The SMC free stator is selected for prototyping, built out of individual laminated components slotted into a $3 \mathrm{D}$ printed nonmagnetic support as shown in Fig. 6 and the photographs of Fig. 7. Fabrication tolerance means there are some visible gaps between these lamination components at joint positons that will affect the equivalent armature reluctance.

The full assembled machine and testing bench are presented in Fig. 8 which is used to perform static DC force and open circuit emf tests.

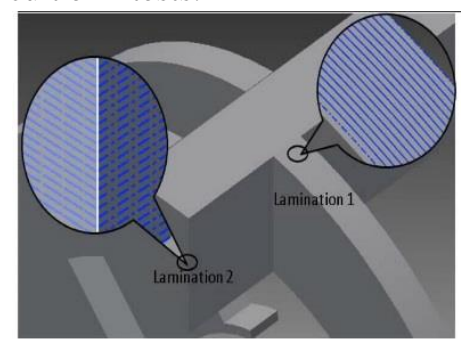

(a) Laminations sketch

Fig. 6. Lamination and support design

Axially laminated teeth

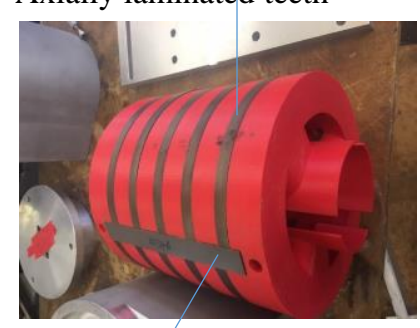

Radially laminated core back

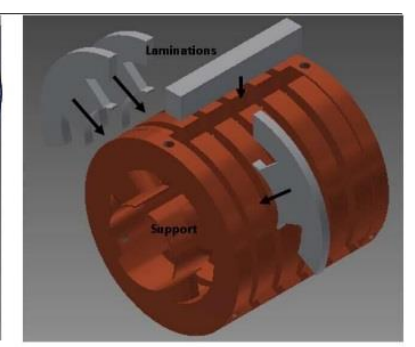

(b) 3D printing support and laminations

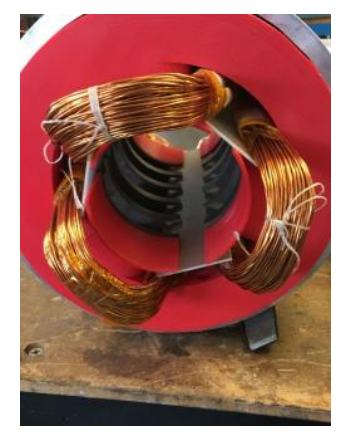

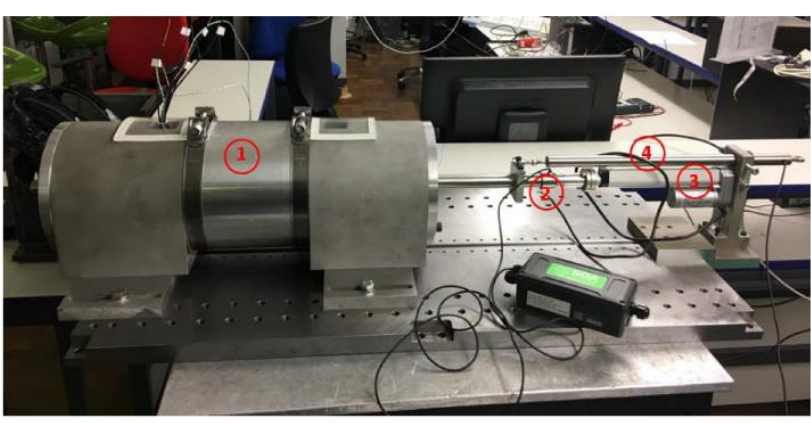

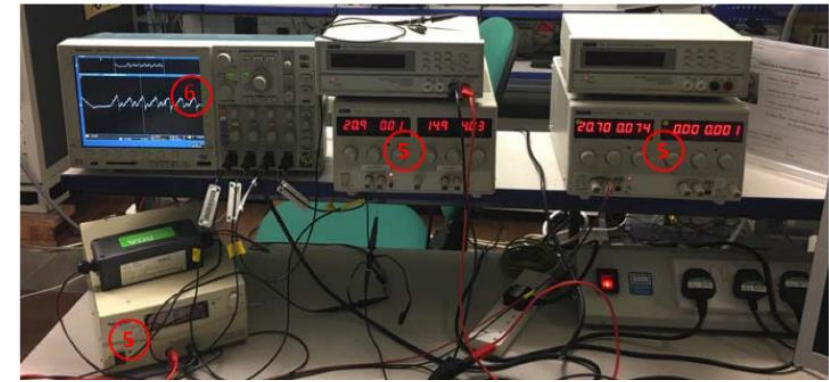

Fig. 8. Testing bench showing: 1 linear machine prototype; 2 load cell; 3 linear actuator; 4 displacement transducer; 5 DC power source units; 6 is the oscilloscope.

\section{B. Static force testing}

Firstly, a constant DC current is applied with slow displacement to investigate a combined profile of the magnetic, reluctance and cogging forces. Secondly, a varied DC current is applied with a fixed translator position to investigate just the magnetic force.

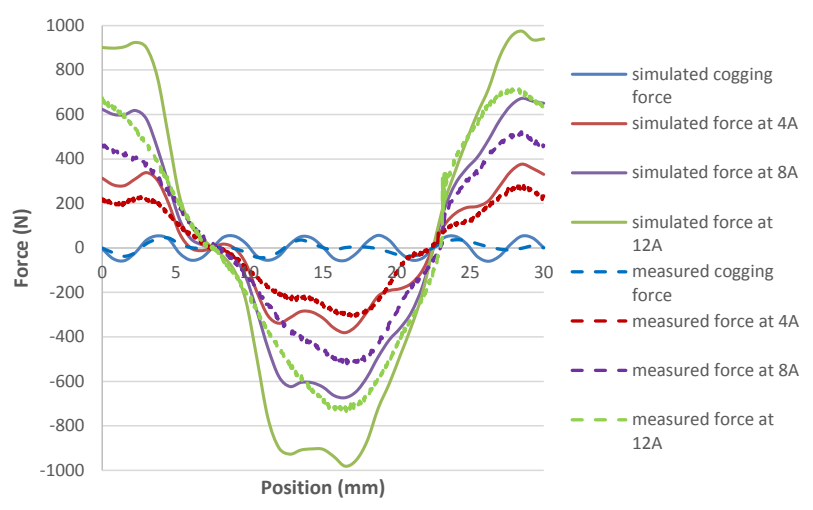

Fig. 9. Simulated and measured force results for constant DC current and varying translator position

For the first test, a very slow constant motion is applied to the translator, starting from the q-axis position (zero magnetic flux) of the measured phase. In the meantime, a constant DC current is applied to the phase winding of a single phase. Simulated force profiles of the idealized design are presented in the solid lines of Fig. 9 with incremental phase currents applied to the phase winding. The cogging force is visible in all force profiles, meanwhile the peak force increases with the DC phase current. The reluctance force is also part of this profile, but due to its small amplitude, it is ignored without losing any generality. Equivalent measured results are presented in the dashed lines of Fig. 9, with a summary of key data in Table I. Compared with the simulations, experimental results of the peak force are about $74.5 \%, 78 \%$ and $73 \%$. Comparison of the 
results shows that the built machine has a much smoother force variation with position throughout the current range. This could be due to the reduced cogging force visible at zero current which implies a poorer reluctance circuit in the built machine than assumed in the finite element analysis, as discussed below in section D. Bearing friction and measurement accuracy will also act to smooth small variations in force.

TABLE I

SIMULATIONS AND MEASUREMENT FOR THE CONSTANT CURRENT TEST

\begin{tabular}{clll}
\hline \hline Peak force $(\mathrm{N})$ & Simulation & Measurement & Ratio \\
\hline $4 \mathrm{~A}$ & 376 & 280 & $74.5 \%$ \\
$8 \mathrm{~A}$ & 672 & 524 & $78.0 \%$ \\
$12 \mathrm{~A}$ & 975 & 715 & $73.0 \%$ \\
\hline \hline
\end{tabular}

During a second static DC current test, the translator is held at the zero cogging position (the $\mathrm{q}$ axis, approximately $2.5 \mathrm{~mm}$ in Fig 9) and the current of a single phase is varied up to 12A. In this manner, test rig friction does not affect the results. Force variation with current is presented in Fig. 10. As the translator is at the zero cogging force position, these results are from the interaction of the two fields - i.e. the electro-magnetic force. The machine is not saturated at the peak current of $12 \mathrm{~A}$ and the divergence between simulated and measured values increases with current. The ratio of measurements to simulations are around $70 \%-75 \%$, as with the first test. The discrepancy can only be due to inaccurate knowledge of the material's permeability characteristic, or imperfections in the magnetic circuit.

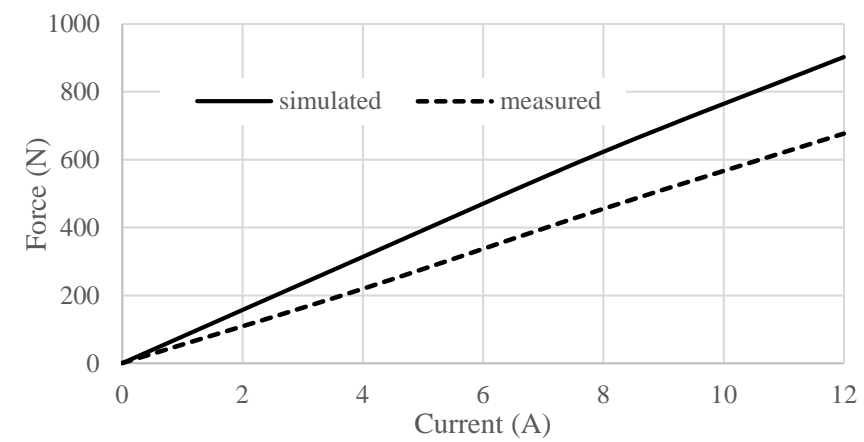

Fig. 10. Simulation and measured peak magnetic force

\section{Transient EMF testing}

Transient tests are carried out by driving the machine with a ball screw. A linear variable differential transformer (LVDT) is used to measure position, which in turn can be used to find instantaneous translator velocity. Fig. 11(a) and 11(b) show the measured position and velocity waveforms for an oscillation of $100 \mathrm{~mm}$ with a peak velocity of $300 \mathrm{~mm} / \mathrm{s}$. Due to the length of the ball screw and limited acceleration, the ideal constant velocity region can only be short. Inspection of Fig. 11 (b) between 0.3 and $0.4 \mathrm{~s}$ shows that in reality there is no true region of constant velocity when using this rig, with a typical variation of $\pm 10 \%$. The emf measured in the three phases over a mechanical cycle is shown in Fig. 11 (c). The waveforms are 120 degrees out of phase and the magnitude varies between the phases.

In Fig. 12, a $100 \mathrm{~ms}$ exert of the experimental results are shown on the same axis as the simulations assuming a fixed speed of $0.3 \mathrm{~m} / \mathrm{s}$. This is the closest segment of the experimental results to constant velocity. Simulated results give a peak of 4.1 $\mathrm{V}$ in each phase, whereas the measured results are between 2.4 and 3.1 V. The agreement between simulation and experimental emf results (58-77\%) is poorer than for the force results in two phases. Errors which equally affect the three phases can potentially be attributed to inaccurate modeling of the materials (magnets and SMC), variation in speed of the translator or parasitic air gaps within the machine. In-balance between phases, however, is assumed to be as a result of translator eccentricity. These latter two affects are investigated below.
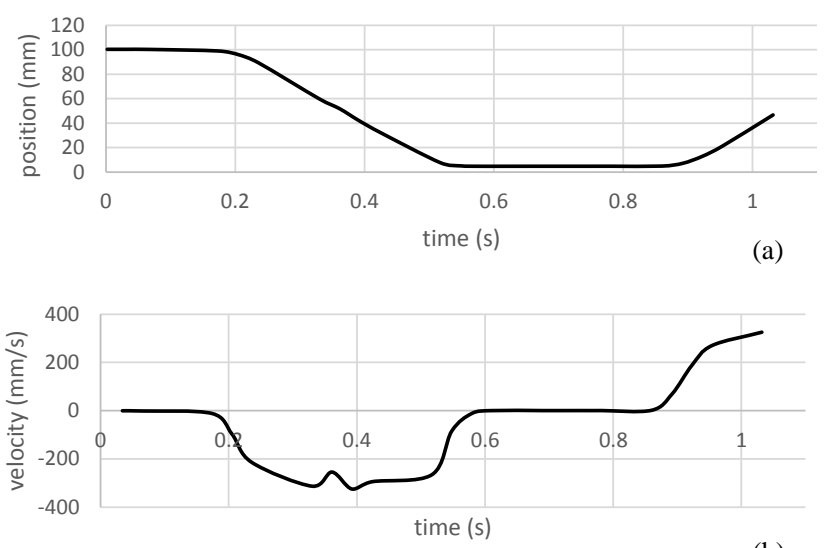

(b)

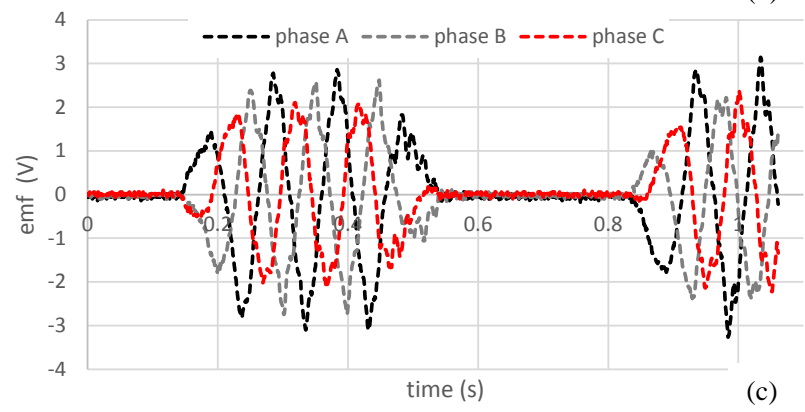

Fig. 11 Prototype results for position, velocity and open circuit emf.

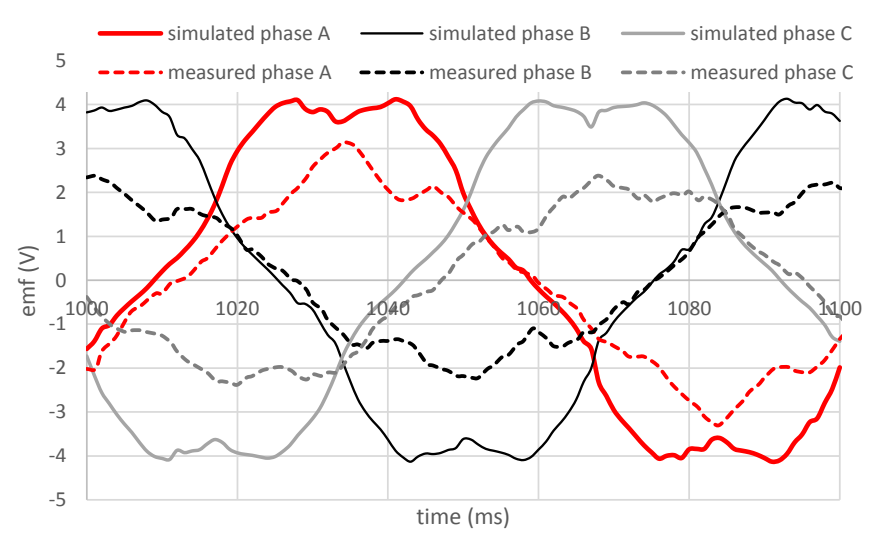

Fig. 12 Simulated and experimental open circuit results at $0.3 \mathrm{~m} / \mathrm{s}$

\section{Manufacturing inaccuracies}

The separate components of the stator are slotted together and held in a 3D printed plastic holder. This was found to give rise to parasitic airgaps between the laminated teeth and bars, visible in Fig. 7. To account for this, the FEA model was adapted as shown in Fig. 13 to include two individual air gaps in the range $0.05 \mathrm{~mm}$ and $0.2 \mathrm{~mm}$ - corresponding to a total 
parasitic air gap per phase between 0.1 and $0.4 \mathrm{~mm}$. At slower peak speeds, the constant velocity region of the rig was more consistent. Simulation and experimental results of back emf at a fixed speed of $0.05 \mathrm{~m} / \mathrm{s}$ are shown in Fig. 14 and RMS values in Table II. The results from the $0.35 \mathrm{~mm}$ total parasitic airgap are closest aligned with the experimental results. It is interesting to note that addition of parasitic gaps reduces the harmonic content of the emf waveform.

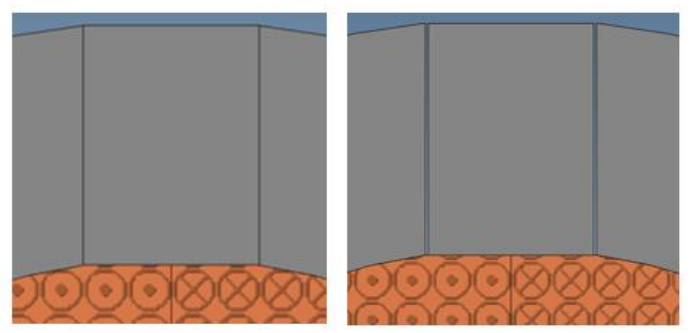

Fig. 13 Parasitic air gaps between components

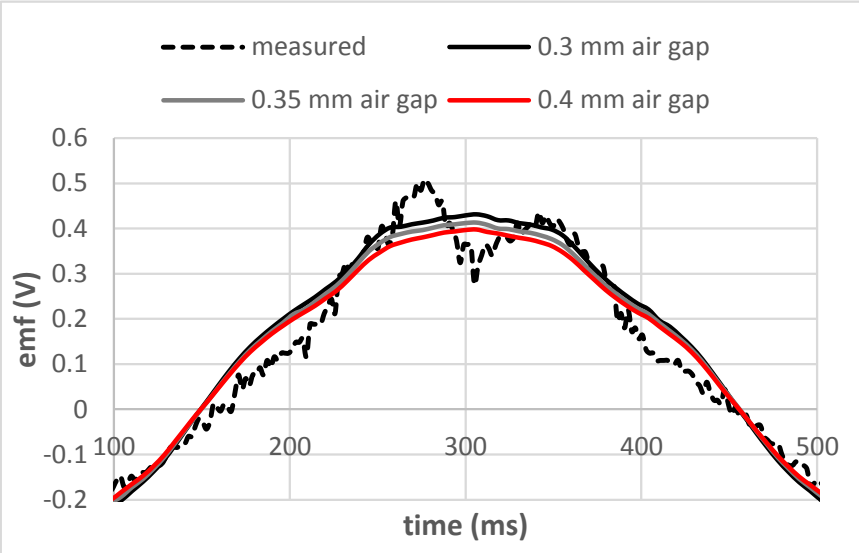

Fig. 14 Variation of simulated back emf with addition of parasitic gaps for a fixed speed of $0.05 \mathrm{~m} / \mathrm{s}$. Values represent summation of total gap for an individual phase

TABLE II

RMS OPEN CIRCUIT EMF VALUES

\begin{tabular}{llll|l}
\hline \hline & \multicolumn{3}{c|}{ Simulated gap size $(\mathrm{mm})$} & measured \\
\cline { 2 - 5 } $\operatorname{Emf}\left(\mathrm{V}_{\mathrm{rms}}\right)$ & 0.3 & 0.35 & 0.4 & \\
\hline \hline
\end{tabular}

The affect of additional airgaps on the force capability within simulations is compared to the measured value in Fig. 15. Again, the closest result to the experimental value implies a total parasitic airgap of $0.35 \mathrm{~mm}$.

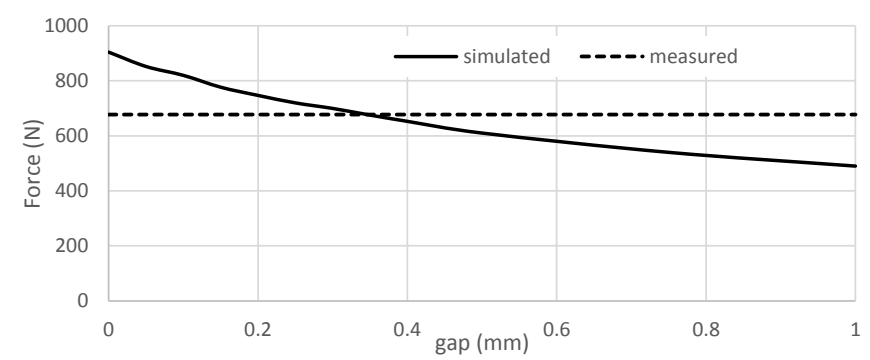

Fig. 15 Simulated peak force at $12 \mathrm{~A}$ verses total parasitic gap length per phase.

\section{E. Translator offset}

When the machine is assembled, the stator casing prevents measurement of the physical airgap between the translator and stator. Fabrication tolerance on the magnets and SMC components was good, and predicted shaft deflection is less than $0.1 \mathrm{~mm}$, however results imply the translator is not concentric within the stator. To understand how translator offset affects machine performance, the transient simulation was run with a translator offset, assuming a shift equally towards one of the coils and equally away from the other two. RMS values of flux linkage varies less than $2 \%$ across the 3 coils in the perfectly centered machine, whereas an offset of $0.5 \mathrm{~mm}$ gave a difference of $16 \%$ between phases.

Using the $0.35 \mathrm{~mm}$ parasitic gap model as the start point, the simulated back emf results for a translator offset for $0-0.25$ $\mathrm{mm}$ are shown in the Table III.

TABLE III

EFFECT OF TRANSLATOR OFFSET ON SIMULATED EMF FOR A FIXED SPEED OF $0.3 \mathrm{M} / \mathrm{s}$ AND ASSUMED PARASITIC GAPS OF $0.35 \mathrm{MM}$

\begin{tabular}{|c|c|c|c|c|c|c|}
\hline & Experimental & \multicolumn{5}{|c|}{ Simulated results with offset (mm) } \\
\hline $\operatorname{Emf}\left(\mathrm{V}_{\mathrm{rms}}\right)$ & & 0 & 0.1 & 0.15 & 0.2 & 0.25 \\
\hline Phase A & 1.41 & 1.66 & 1.58 & 1.53 & 1.49 & 1.45 \\
\hline Phase B & 1.66 & 1.66 & 1.75 & 1.78 & 1.82 & 1.87 \\
\hline Phase C & 1.31 & 1.66 & 1.58 & 1.53 & 1.49 & 1.45 \\
\hline $\begin{array}{l}\text { Per } \\
\text { offset }\end{array}$ & & & & & & \\
\hline$(\mathrm{A}+\mathrm{C}) / 2 \mathrm{~B}$ & 0.82 & 1 & 0.9 & 0.86 & 0.82 & 0.77 \\
\hline
\end{tabular}

Using the per unit offset defined in Table III, the $0.2 \mathrm{~mm}$ translator gives the best prediction compared to experimental data and this is presented in Fig. 16. The RMS simulation error in this case is $6-14 \%$ across the three phases - comparable with the uncertainty in the velocity profile.

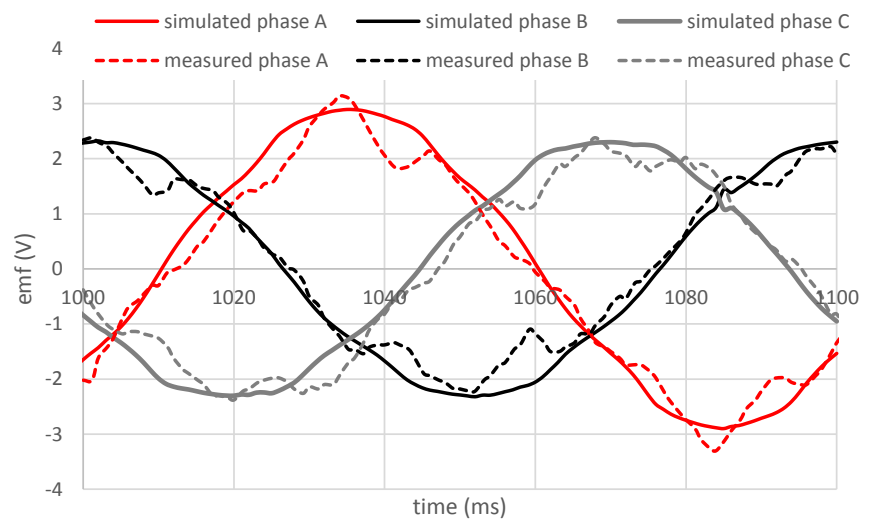

Fig. 16 Simulated (a) and experimental (b) high speed test back EMF, using modified FEA model to account for airgaps and offset translator

\section{NUMERICAL ANALYSIS}

\section{A. Swapped Loading}

In $[1,10]$ an effective way of deriving the thrust force for a transverse flux machine by swapping magnetic loading $(B)$ and electric loading $(A)$ was presented. The magnets were replaced with equivalent current sheets to give $A$ and the air gap flux density $B$ is produced by the armature current. Fig 17 gives a single phased circumferential-view sketch of the prototype, with magnets replaced by current sheets (dots and crosses). When the translator is at the peak thrust force position (magnets 
aligned with stator teeth), the peak armature current is applied to the phase windings. At this point the armature field flux can be classified into three components as: main flux $\left(\phi_{\mathrm{po}}\right)$, fringing flux $\left(\phi_{\text {ne }}\right)$ and leakage flux ( $\left.\phi_{\text {leak }}\right)$.

The red line through the highly permeable steel tooth in Fig. 17 is the main flux which can produce a positive thrust force $\left(F_{p o}\right)$. The fringing flux is denoted by a red dashed line through the low permeable 'air tooth' and produces a negative thrust force $\left(F_{n e}\right)$ The green line is the leakage flux which does not contribute to the thrust force.

The net thrust force is the difference of $F_{p o}$ and $F_{n e}$. Detailed derivations are formulated in (1), where Area is the effective area between armature tooth and translator equivalent current sheets, $M M F_{e q}$ is the equivalent magnetic motive force of the magnet, $L_{e q}$ is the effective current length, $B_{s}$ is the radial flux density which produces the thrust force, $K_{B}$ is defined as the flux factor in [18] [19] and in (3) section VI.B below, and is typically only $32 \%$ or less in transverse flux machines, $M$ is the magnetization or coercivity of magnets and $d_{m}$ is the magnet depth.

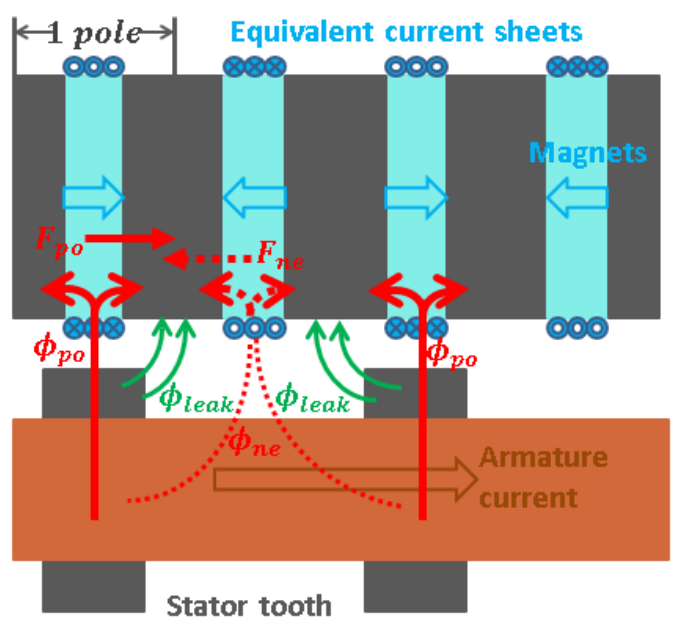

Fig. 17. Swapped loading method for the final designed MPM

$$
\begin{aligned}
F_{\text {peak }} & =F_{p o}-F_{n e}=\frac{\phi_{p o}-\phi_{n e}}{\text { Area }} \times M M F_{e q} \times L_{e q} \\
& =\frac{\left(\phi_{p o}+\phi_{n e}\right)}{\text { Area }} \times \frac{\phi_{p o}-\phi_{n e}}{\phi_{p o}+\phi_{n e}} \times M M F_{e q} \times L_{e q} \\
& =\frac{\left(\phi_{p o}+\phi_{n e}\right)}{A r e a} \times \frac{B_{p o}-B_{n e}}{B_{p o}+B_{n e}} \times M M F_{e q} \times L_{e q} \\
& =B_{S} \times K_{B} \times M M F_{e q} \times L_{e q} \\
M M F_{e q} & =M \times d_{m}
\end{aligned}
$$

In this topology, flux density varies in both radial and axial directions of the translator outer circumference, as shown in Fig. 18 (single phased, for example). The flux density is higher in the area close to the steel tooth whereas the flux density for the air tooth is weaker. Detailed simulated FEA data for both $B_{p o}$ and $B_{n e}$ are shown in Fig. 19(a) and (b). In reality the thrust force is generated all along the magnets' equivalent sheets, however due to the constancy of equivalent current sheets, the average flux density value can be taken into account without losing generality. Seven points are used to calculate average flux density for $B_{p o}$ and $B_{n e}$ respectively ( $z 1$ to $z 7$ and $z 8$ to $z 14$ ) as a compromise between accuracy and computation time.

Flux density profiles along a single phase span are shown later in Fig. 24, where the blue curve is the profile of the average $B_{p o}$, the red curve is the average $B_{n e}$ and the green curve is the difference of $B_{p o}$ and $B_{n e}$ (or effective flux density). The constancy of equivalent current sheets not only applies to the translator moving direction but also the phase arc span. Thus when calculating the effective thrust force, mean values of average flux density profiles are required as $B_{p o}, B_{n e}$ and $B_{p o}-$ $B_{n e}$ equal to $0.59 \mathrm{~T}, 0.11 \mathrm{~T}$ and $0.48 \mathrm{~T}$ respectively. In this case since the steel tooth and air tooth share the same effective area thus the flux density factor can represent the flux factor as $\frac{0.48}{0.59+0.11}=68.6 \%$. However by observing Fig. 18 there is still considerable leakage flux which contributes nothing to the thrust force, the designer will consider this component in the numerical solution section to extract $B_{p o}, B_{n e}$ and $B_{p o}-B_{n e}$. By substituting mean values of flux density profiles from Fig. 19 and using the dimensions from Table IV into (1) the thrust force for a single phase and single pole pair model at this position can be estimated as: Thrust $=B_{s} \times K_{B} \times \mathrm{M} \times d_{m} \times 120 / 360 \times$ $2 \pi \times r=(0.59+0.11) T \times 68.57 \% \times 827600 \times 0.006 \times$ $120 / 360 \times 2 \pi \times 0.0394=197 N$ For three phased 5 pole paired topology the equivalent thrust force is approximately: Thrust $=1.5 \times 5 \times 197=1477.5 \mathrm{~N}$ which is close to the simulated value $(200 \times 1.5 \times 5=1500 \mathrm{~N})$.

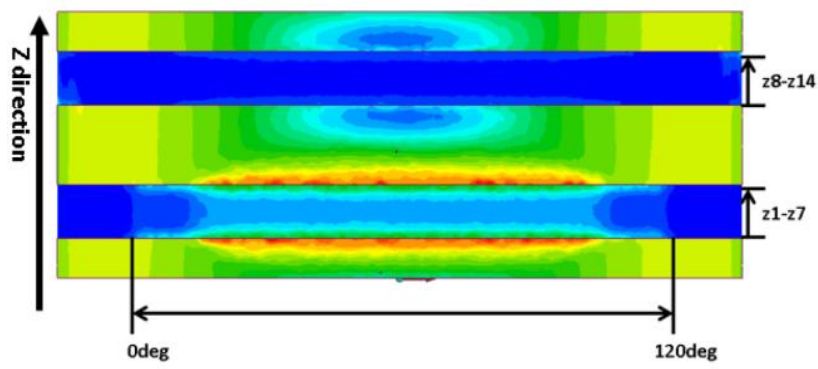

Fig. 18. Flux density variation along the translator surface (single phase)

TABLE IV

MACHINE DETAILED DIMENSIONS AND PARAMETERS

\begin{tabular}{ll} 
Translator inner radius $(\mathrm{m})$ & 0.026 \\
Translator core back depth $(\mathrm{m})$ & 0.0129 \\
Translator outer radius $(\mathrm{m})$ & 0.0389 \\
Air gap $(\mathrm{m})$ & 0.001 \\
Tooth arc (degree) & 60 \\
Tooth height $(\mathrm{m})$ & 0.029 \\
Stator core back depth (m) & 0.026 \\
Stator core back inner radius (m) & 0.0689 \\
Stator core back outer radius (m) & 0.0949 \\
Translator magnet depth (m) & 0.006 \\
Translator steel depth $(\mathrm{m})$ & 0.009 \\
Stator tooth depth $(\mathrm{m})$ & 0.009 \\
Pole pair pitch $(\mathrm{m})$ & 0.03 \\
Phase angle $\beta$ & 0 \\
Max current density $\left(\mathrm{A} / \mathrm{mm}^{2}\right)$ & 3.5 \\
Max single phase peak thrust $(\mathrm{N})$ & 200 \\
Power factor & 0.62 \\
\hline
\end{tabular}



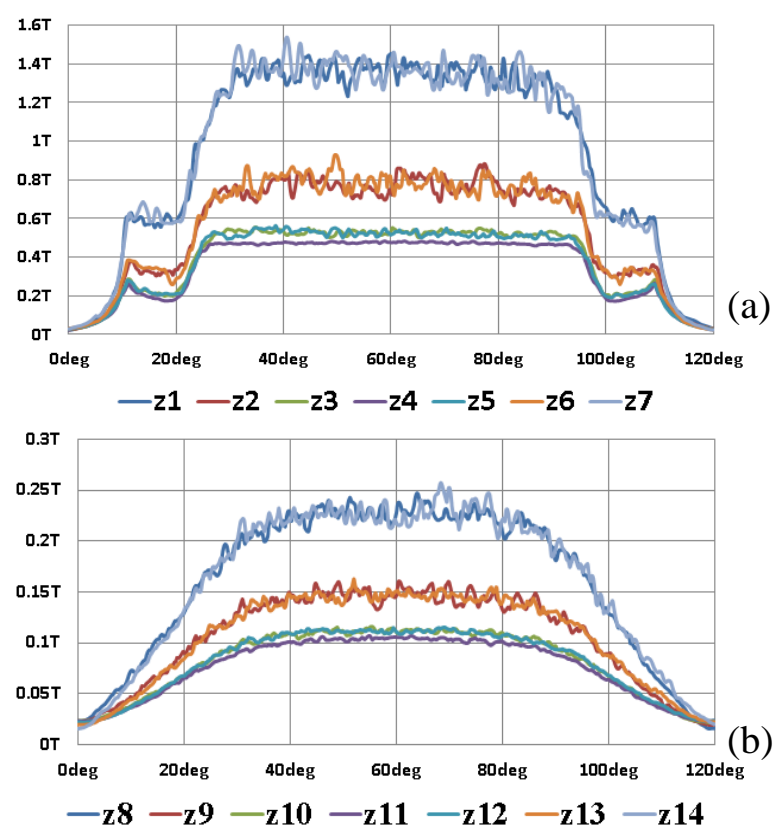

Fig. 19. Detailed flux density profiles

\section{B. Flux Factor and Flux Linkage Factor}

Fig. 20 shows a flux density plot and a simplified flow chart to explain the concept of the flux factor and flux linkage factor. Where the red block $(a)$ is the flux which produces positive thrust force (main flux, $\phi_{\mathrm{po}}$ ), the black block $(b)$ is the flux which produces negative thrust force (fringing flux, $\phi_{\text {ne }}$ ) and the green blocks $(c)$ are the leaked flux ( $\left.\phi_{\text {leak }}\right)$, which contributes nothing to the thrust force. The sum of $a, b$ and $c$ is the total flux produced by the armature current. The flux linkage factor $\left(K_{L}\right)$ and the flux factor $\left(K_{B}\right)$ are defined in (2) and (3).

$$
\begin{gathered}
K_{L}=\frac{\emptyset_{p o}+\emptyset_{n e}}{\emptyset_{p o}+\emptyset_{n e}+\emptyset_{\text {leak }}}=\frac{a+b}{a+b+c} \\
K_{B}=\frac{\emptyset_{p o}-\emptyset_{n e}}{\emptyset_{p o}+\emptyset_{n e}}=\frac{a-b}{a+b}
\end{gathered}
$$

For the prototype, simulated results show the flux linkage factor $K_{L}$ is $38 \%$ and the flux factor $K_{B}$ is $68.6 \%$.

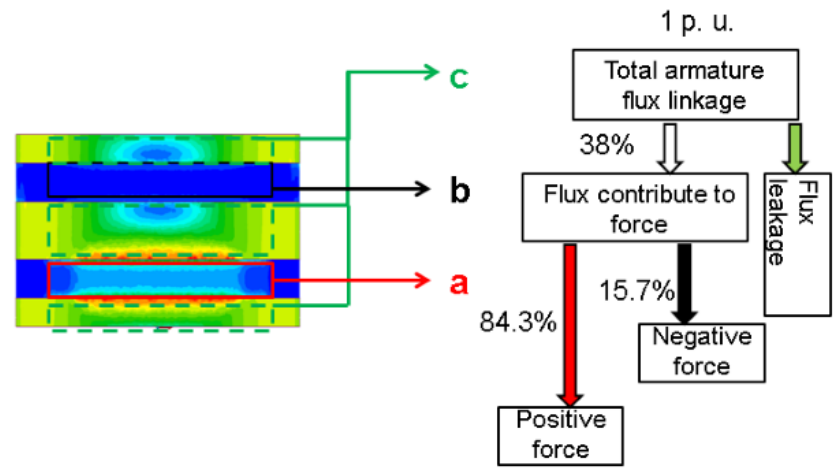

Fig. 20. Flux distribution sketch for prototype. $a, b, c$ are used in (2) and (3)

\section{Reluctance network}

In the above sections, all results related to the flux profiles are extracted from 3D FEA simulations. However a drawback of this is the computation time cost (typically 3-4 hours for static solver and 18-24 hours for transient). In this section the values of $B_{p o}-B_{n e}, K_{B}$ and $K_{L}$ will be calculated using a simplified 3D reluctance network model based on magnetic equivalent circuit as introduced in [20,21].

An example drawing of the reluctance network at zero electric degree position is shown in Fig. 21. The modelling is mainly divided into 3 parts representing the stator tooth, the translator and the stator core-back. The stator tooth contains three separate phases with 8 columns for each phase along a pole pair pitch, the translator part contains 4 columns and the stator core-back is a single unit which is conducted between different phases. Rows for each phase include: steel tooth reluctance and air tooth reluctance, air gap reluctance, air joint reluctance and steel joint reluctance. The general layout of the reluctance network is almost unaffected by the position, however the material and values do vary. For example, the stator tooth part of phase $\mathrm{A}$ or $\mathrm{C}$ can be regarded as that of phase $\mathrm{B}$ at another position.

Two assumptions are made when calculating the flux density profiles in this 3D reluctance network model: Firstly, all steel components share the same relative permeability at every different position (since the position is changed the armature current is changed in a sinusoidal manner and the permeability needs to be recalculated based on the B-H curve of the material); secondly for each phase the air gap flux density is circumferentially constant between $30-90^{\circ}$ mechanical and linearly drops to zero from $30^{\circ}-0^{\circ}$ and $90^{\circ}-120^{\circ}$.

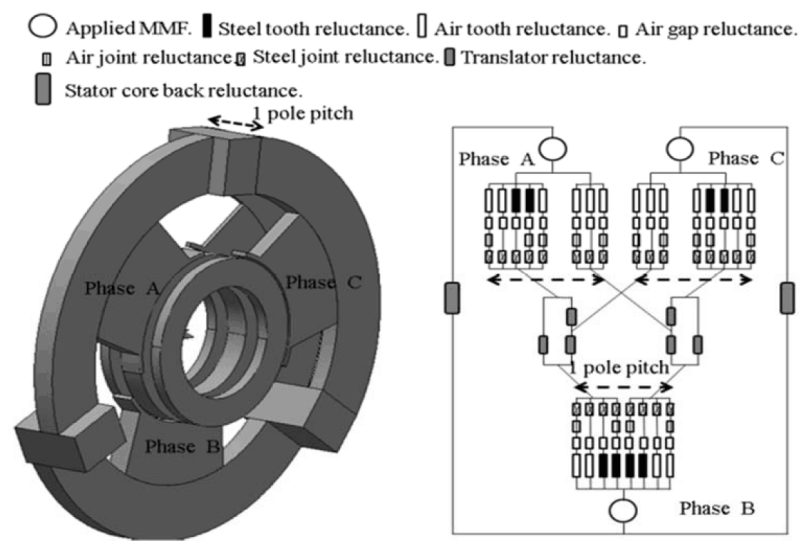

Fig. 21. 3D model and 3D reluctance network drawing

After confirming the reluctance network topology then it becomes possible to determine the reluctance value for each component according to the size specification given in Table IV and (4), where $R_{e q}$ is the equivalent reluctance for the component, $L_{e q}$ is the equivalent component length, $\mu_{\mathrm{r}}$ is the relative permeability, $\mu_{0}$ is the permeability constant and $A_{\mathrm{eq}}$ is the equivalent component cross section area. The relative permeability is estimated by the flow chart shown in Fig. 22 and the final value is 7676 . The Simulink model of the reluctance network with detailed results is as shown in Fig. 23, where Display and Displayl denote half of the leaked flux, Display2 denotes half of the positive flux, Display3 denotes half of the negative flux and Display4 is the total flux value. As a result $\phi_{\text {leak }}$ is $0.4164 \mathrm{mWb}, \phi_{\mathrm{po}}$ is $0.1842 \mathrm{mWb}, \phi_{\text {ne }}$ is $0.03 \mathrm{mWb}$ and $\phi_{\text {total }}$ is $0.6306 \mathrm{mWb}$, thus $K_{L}$ is about $34.0 \%$ and $K_{B}$ is about 
$72.0 \%$ (compared with $38 \%$ and $68.6 \%$ from simulations). If taking the effective cross sectional area into account $\left(30-90^{\circ}\right.$ of a phase span with $6 \mathrm{~mm}$ magnet width) then peak $B_{p o}$ is 0.755 $\mathrm{T}$ and peak $B_{n e}$ is $0.123 \mathrm{~T}$. Thus the corresponding flux density profiles from calculations are as shown in Fig. 24, which gives values for $B_{p o}, B_{n e}$ and effective flux density of $0.566 \mathrm{~T}, 0.092$ $\mathrm{T}$ and $0.474 \mathrm{~T}$ respectively, compared to simulated results $(0.59$ $\mathrm{T}, 0.11 \mathrm{~T}$ and $0.48 \mathrm{~T})$. The numerical reluctance network method thus shows a good agreement with an error less than $2 \%$ on the effective flux density.

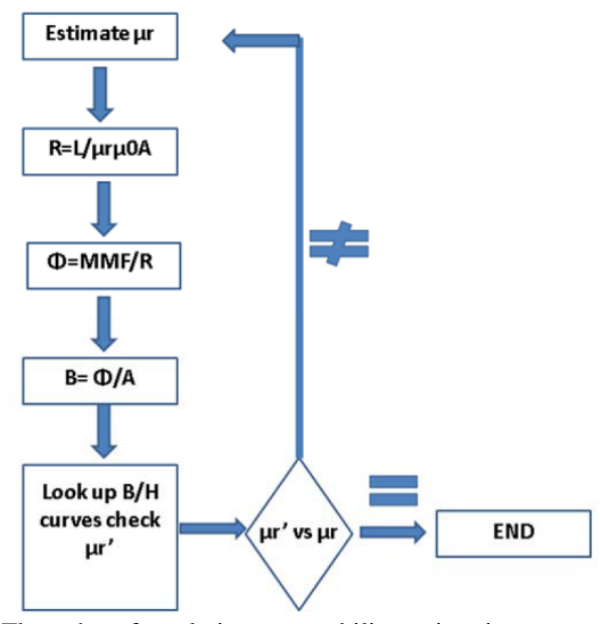

Fig. 22 Flow chart for relative permeability estimation

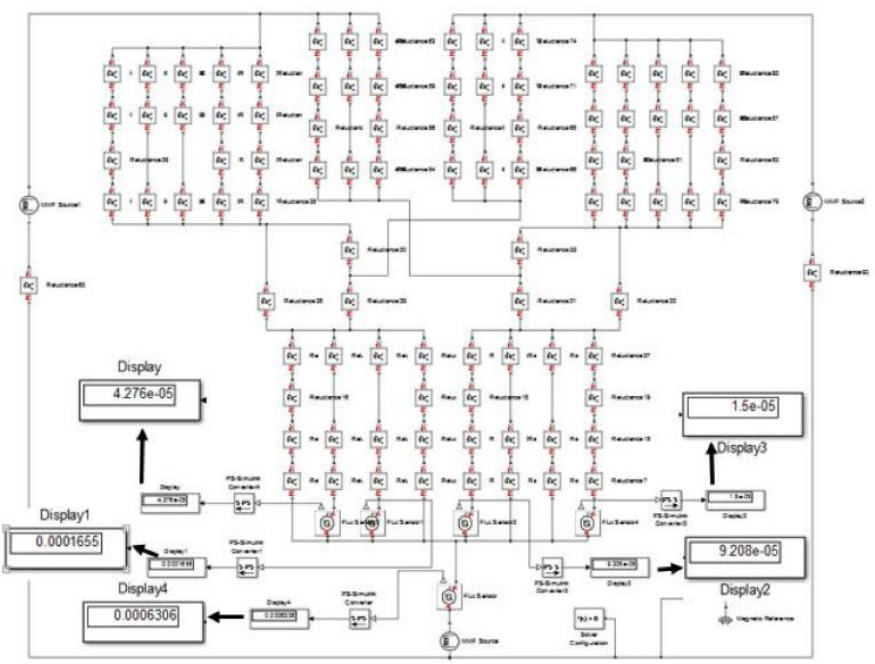

Fig. 23 Reluctance network Simulink model

$$
R_{e q}=\frac{L_{e q}}{\mu_{r} \times \mu_{0} \times A_{e q}}
$$

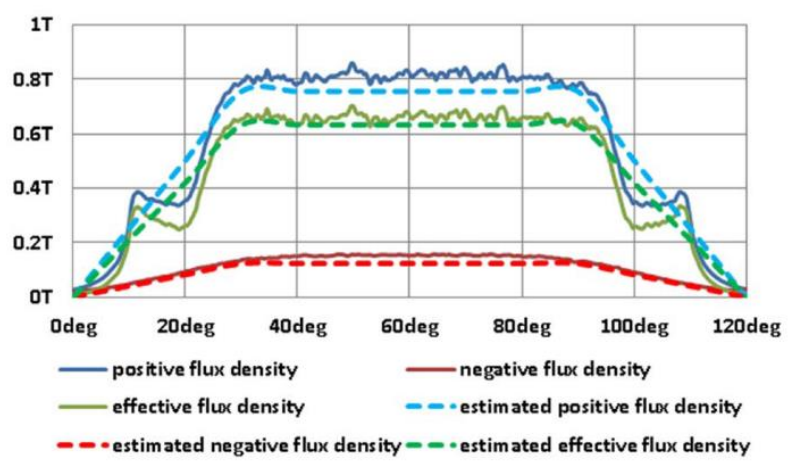

Fig. 24. Numerical and simulated flux density profile comparison

\section{Power Factor}

In (5) a relationship between the power factor and $K_{B}$ and $K_{L}$ is given, where $R_{e q}$ is the equivalent reluctance of the machine component, $v$ is the linear speed in $\mathrm{m} / \mathrm{s}$ and $p_{\tau}$ is the pole pair pitch in $\mathrm{m}$. As a result it can be seen that the power factor is related to both flux linkage factor $K_{L}$ and flux factor $K_{B}$. Since Area, $M M F_{e q}, L_{e q}$ and $E_{\text {fconstant }}$ are all related to dimensions and material, both of which are constant, for a specific thrust force requirement a higher value of $K_{L}$ and $K_{B}$ will give a higher power factor.

$$
\begin{aligned}
B_{S} & =\frac{\phi_{\text {total }} \times K_{L}}{\text { Area }}=\frac{I_{a} \times K_{L}}{R_{\text {eqtotal }} \times \text { Area }} \\
I_{a} & =\frac{F_{\text {peak }} \times R_{\text {eqtotal }} \times \text { Area }}{K_{L} \times K_{B} \times M M F_{e q} \times L_{e q}} \\
L_{q} & =\frac{1}{R_{\text {eqtotal }}} \\
W_{e} & =\frac{2 \pi \times v}{p_{\tau}} \\
P F & =\cos \left(\tan ^{-1} \frac{I_{a} \times L_{q} \times \omega_{e}}{E_{f}}\right) \\
& =\cos \left(\tan ^{-1} \frac{F_{\text {peak }} \times \text { Area }}{K_{L} \times K_{B} \times M M F_{e q} \times L_{e q} \times E_{\text {fconstant }}}\right)
\end{aligned}
$$

Using (5) and simulation results, the thrust force, effective flux density, $K_{L}, K_{B}$ and power factor profiles with different armature current densities are as shown in Fig 25 (Solid lines for calculations and dash lines for simulations). It can be observed that as the current density increases from 1 to 3.5 $\mathrm{A} / \mathrm{mm}^{2}$, the thrust force profile shares the same trend as the effective flux density profile in the per-unit form, $K_{L}$ and $K_{B}$ essentially keep constant and the power factor gradually drops from 0.8 and finally converges to 0.62 . Thus it can be concluded that the power factor variation matches the regulation as mentioned in (5) and the prototype can reach 0.62 power factor for the worst-case scenario. Compared to power factors of 0.35 0.53 reported in [22] and elsewhere, the deigned machine shows better performance due to the higher value $K_{B}$. However due to intrinsically low $K_{L}$, the TFM still shows a poor power factor compared to conventional longitudinal flux machines. $K_{L}$ should perhaps be considered the dominant driver of low power factor in these machines. 


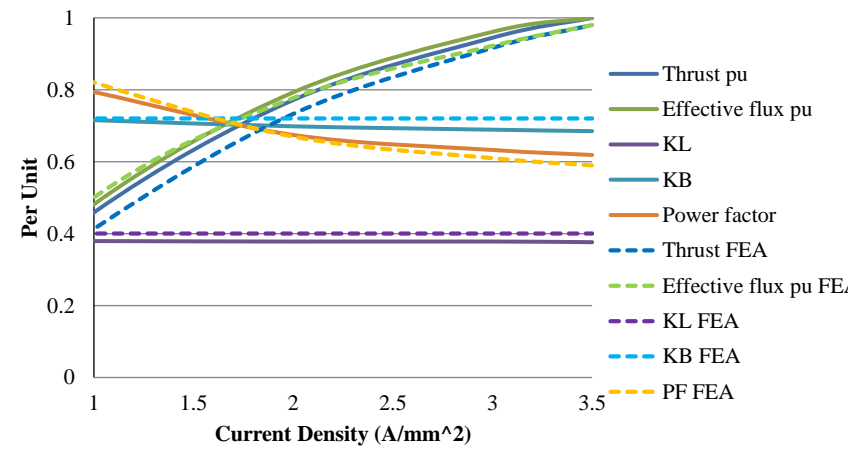

Fig. 25. Per unit force verses current density. Solid lines are numerical, dashed are FEA simulations.

\section{E. Case studies}

Two case studies are presented to highlight the importance of the pole pair number to $K_{L}$ and $K_{B}$ thus the machine performances (thrust force and power factor). Both calculations are based on the swapped loading method and the equivalent reluctance network, although FEA results are included for validation.

\section{1) Pole pair number}

The first case study investigates machine performance with an increasing number of pole pairs (from 1 to 5) under a constant armature current. Fig. 26 shows that $K_{B}$ remains relatively constant whereas both $K_{L}$ and the total flux increases. These effects are due to the distance between adjacent translator iron cores reducing whilst the other reluctance components remain constant. As a result, when the armature current profile is set as a constant, the total flux increases from 0.79 to 1 per unit and $K_{L}$ varies from 0.14 to 0.38 per unit. By combining both the total flux and $K_{L}$ profiles the effective flux density profile can be calculated and shows agreement to the thrust force profile in the per-unit form. In general the first study proves that increasing pole pair number can effectively increase $K_{L} \times K_{B}$ thus contributes to higher thrust force.

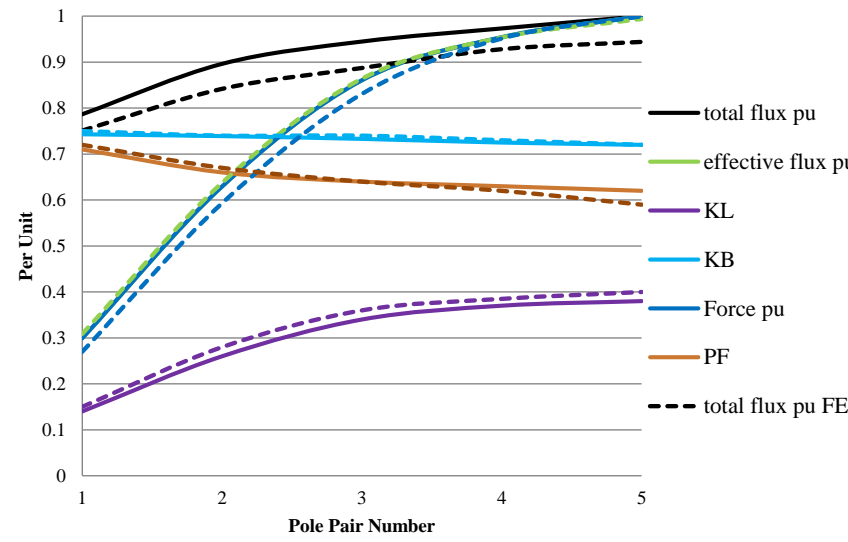

Fig. 26. Performance of machines on different pole pair numbers with a constant armature current

\section{2) $K_{B} K_{L}$ and power factor for fixed force}

The second case study is a validation of the relationship between $K_{B}$ and $K_{L}$ and the power factor when the same thrust force $(380 \mathrm{~N})$ is applied to the models of different pole pair number by altering the applied MMF. In Fig. 27, $K_{L}$ and $K_{B}$ show similar trends as those in Fig. 26. The required armature current (or total flux) reduces from 1 p.u. (1 pole pair) to 0.53 p.u. (5 pole pairs), however because $K_{L}$ improves with increasing pole pair numbers, the effective flux and the thrust force remains constant. The resulting power factor improves from 0.71 ( 1 pole pair) to 0.89 ( 5 pole pairs), it again proves the increasing $K_{L} \times K_{B}$ contributes to a higher power factor.

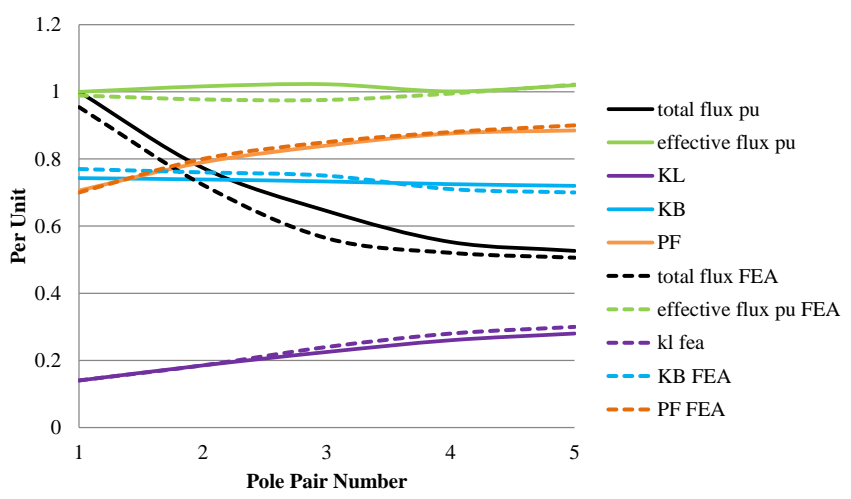

Fig. 27. Per unit MMF verses pole pair number with a constant thrust

\section{CONCLUSION}

In this paper, a new layout of cylindrical transverse flux linear machine has been discussed, analyzed and built. Despite the three dimensional flux path, a stator made purely of laminated parts is proposed and demonstrated, consisting of separate segments held together in a non-magnetic structure. The novel combined phase, single tooth stator surrounds a soft magnetic composite translator. Experimental static force and transient EMF tests are presented and used to investigate the influence of manufacturing challenges on this new concept. Results imply the existence of parasitic gaps in the stator and a non-concentric stator.

A reluctance network has been used to give new insight into the relationship between power factor and thrust. Two factors: $K_{B}$ and $K_{L}$ have been used to investigate thrust force and power factor. In other literature $K_{B}$, which is related to the ratio of flux which contributes positively to force and flux which opposes the main force, is often blamed for low power factor. In this work, it was found that $K_{L}$, the ratio of main to leakage flux, is the dominant factor.

\section{REFERENCES}

[1] H. Kosaka, T. Akita, K. Moriya, S. Goto, Y. Hotta, T. Umeno, and K. Nakakita, 2014. "Development of free piston engine linear generator system Part 1-investigation of fundamental characteristics" (No. 2014-01 1203). SAE Technical Paper. 2014-01-1203, 2014.

[2] S. Goto, K. Moriya, H. Kosaka, T. Akita, Y. Hotta, T. Umeno, and K. Nakakita, 2014. "Development of free piston engine linear generator system part 2-investigation of control system for generator" (No. 201401-1193). SAE Technical Paper. 2014-01-1193, 2014,

[3] J. R. Anglada, S. M. Sharkh, "Analysis of Transverse Flux Machines using a Virtual Mutual Inductance Approach", IEEE Trans. on Energy Conv., 2017

[4] H.M. Hasanien, A.S. Abd-Rabou, and S.M. Sakr, 2010. "Design optimization of transverse flux linear motor for weight reduction and performance improvement using response surface methodology and genetic algorithms." IEEE Trans on Energy Conv, 25(3), pp.598-605. 
[5] S. Jordan, N.J. Baker, J.G. Washington, G.J. Atkinson and E. Pinguey, "Construction Methods for Modulated Pole Machines", IEEE Int. Electric Machines and Drives Conf (IEMDC). 2017, Miami, FL, USA

[6] J. Wang, N.J. Baker, "Comparison of flux switching and modulated pole linear machines for use with a free piston" IEEE Int. Electric Machines and Drives Conf (IEMDC), 2015: 642-648.

[7] J. Wang, N.J. Baker, “A comparison of alternative linear machines for use with a direct drive free piston engine", 8th IET International Conference on Power Electronics, Machines and Drives (PEMD), 2016, UK

[8] N.J. Baker, J. Wang, G.J. Atkinson, "Optimization and comparison of linear transverse flux and flux switching machines" IEEE Int. conf. on Electrical Machines (ICEM), 2016

[9] H. Yu-Sheng, T. Mi-Ching, "Development of a Novel Transverse Flux Wheel Motor" IEEE Trans. on Magn., 2011, Vol 47, Issue: 10 pp $3677-$ 3680

[10] N. J. Baker; G. J. Atkinson; J. G. Washington; B. C. Mecrow; G. Nord; L. Sjoberg "Design of high torque traction motors for automotive applications using modulated pole SMC machines". Int. Conf. on Power Electronics, Machines and Drives (PEMD), 2012

[11] H. Polinder, B.C. Mecrow, A.G. Jack, P.G. Dickinson, M.A. Mueller, "Conventional and TFPM linear generators for direct-drive wave energy conversion", IEEE Trans on Energy Conv., vol 20 pp260- 2672005

[12] G. Lei, C. Liu, Y. Guo, J. Zhu, "Multidisciplinary Design Analysis and Optimization of a PM Transverse Flux Machine with Soft Magnetic Composite Core", IEEE Trans on Magn, 2015, Issue: 99

[13] K. Lu; W. Wu, "High Torque Density Transverse Flux Machine Without the Need to Use SMC Material for 3-D Flux Paths", IEEE Trans Magn, 2015, Vol51 issue 3

[14] J.G. Washington, G.J. Atkinson, N.J. Baker, A.G. Jack, B.C. Mecrow, B.B. Jensen, L. Pennander, G.L. Nord, L. Sjöberg, "Three- Phase Modulated Pole Machine Topologies Utilizing Mutual Flux Paths", IEEE Trans on Energy Conv, Vol 2 pp507-515 2012

[15] H.M. Hasanien, A.S. Abd-Rabou, S.M. Sakr, "Design Optimization of Transverse Flux Linear Motor for Weight Reduction and Performance Improvement Using Response Surface Methodology and Genetic Algorithms", IEEE Trans. on Energy Conv., 2010, pp598-605, vol 25

[16] J.G. Washington, G.J. Atkinson, N.J. Baker, A.G. Jack, B.C. Mecrow, B.B. Jensen, L. Pennander, G. Nord, L. Sjoberg, "Three-Phase Modulated Pole Machine Topologies Utilizing Mutual Flux Paths", IEEE Trans. on Energy Conv, Vol. 27, No. 2, June 2012

[17] J.R. Anglada, and S. Sharkh, "An insight into torque production and power factor in transverse-flux machines". IEEE Trans. on Industry Apps., 2017

[18] M.R. Harris, and B.C. Mecrow, "Variable reluctance permanent magnet motors for high specific output." IEE Int Conf Electrical Machines and Drives, 1993. (pp. 437-442).

[19] M.R. Harris, G.H. Pajooman, and S.A. Sharkh, "Performance and design optimisation of electric motors with heteropolar surface magnets and homopolar windings". IEE Pr.-Elec Power Apps, 1996, 143(6), pp.429436.

[20] A. Cosic, C. Sadarangani, and M. and, "3D analyses of a novel Transverse Flux machine for a free piston energy converter". In Int. conf. Electrical Machines (ICEM), 2008.

[21] P. Zheng, S. Zhu, B. Yu, L. Cheng, and Y. Fan, "Magnetic circuit analysis and performance improvement of a tubular staggered-tooth transverseflux linear machine for free-piston energy converter". IEEE Int. Conf. on Magn. (INTERMAG), 2015 IEEE (pp. 1-1). IEEE.

[22] M.R. Harris, G.H. Pajooman, S.A. Sharkh, "The problem of power factor in VRPM (transverse-flux) machines" Eighth International Conference on Electrical Machines and Drives (Conf. Publ. No. 444), 1997 